\title{
Thermo-Physical Properties of Al-Mg Alloy in Liquid State at Different Temperatures
}

\author{
Shashit Kumar Yadav1, Lok Narayan Jha², Arjun Dhungana ${ }^{3}$, Upendra Mehta ${ }^{3}$, \\ Devendra Adhikari ${ }^{*}$
}

\footnotetext{
${ }^{1}$ Department of Physics, Surya Narayan Satya Narayan Morbaita Yadav Multiple Campus, Tribhuvan University, Siraha, Nepal ${ }^{2}$ Central Department of Physics, Tribhuvan University, Kirtipur, Nepal

${ }^{3}$ Department of Physics, Mahendra Morang Adarsha Multiple Campus, Tribhuvan University, Biratnagar, Nepal

Email: *adksbdev@yahoo.com
}

How to cite this paper: Yadav, S.K., Jha, L.N., Dhunganam A., Mehta, U. and Adhikari, D. (2018) Thermo-Physical Properties of Al-Mg Alloy in Liquid State at Different Temperatures. Materials Sciences and Applications, 9, 812-828.

https://doi.org/10.4236/msa.2018.910058

Received: July 23, 2018

Accepted: September 8, 2018

Published: September 11, 2018

Copyright $\odot 2018$ by authors and Scientific Research Publishing Inc. This work is licensed under the Creative Commons Attribution International License (CC BY 4.0).

http://creativecommons.org/licenses/by/4.0/

\begin{abstract}
Thermo-physical properties of Al-Mg alloys in molten state at $1073 \mathrm{~K}$ have been studied using thermodynamic modeling. Thermodynamic properties, such as free energy of mixing, heat of mixing, entropy of mixing, activities and structural properties, such as concentration fluctuation in long wavelength limit, Warren-Cowely short range order parameter have been studied at $1073 \mathrm{~K}, 1173 \mathrm{~K}, 1273 \mathrm{~K}$ and $1373 \mathrm{~K}$ on the basis of regular associated solution model. The surface properties such as surface concentrations and surface tension of the liquid alloys have been studied by using Butler's model. A consistent set of model parameters have also been obtained by using optimization procedure based on statistical thermodynamics. Our analysis reveals that $\mathrm{Al}-\mathrm{Mg}$ alloy is moderately interacting and it shows ordering nature at $1073 \mathrm{~K}$. The nature of the alloys changes from ordering to segregating as the temperature increases.
\end{abstract}

\section{Keywords}

True Mole Fraction, Pairwise Interaction Energy, Temperature Derivative Terms, $\mathrm{Al}_{3} \mathrm{Mg}_{2}$ Complex, Optimization Procedure

\section{Introduction}

The properties such as light weight and excellent corrosion resistance make Al-based alloys suitable for developing engineering structures and their components. Because of these properties Al-based alloys have been extensively used in aircraft, automotive engines and architecture [1] [2] [3]. Apart from aforementioned properties, Al-Mg alloys have other very valuable properties, such as high 
mechanical strength, good crack resistance, low cost maintenance, non-toxic, non-magnetic and much less inflammable than any other Al-based alloys. This is why a considerable attention has been given by metallurgist in developing $\mathrm{Al}-\mathrm{Mg}$ alloys because of the possibilities of their uses in electrical industry, roofing sheets, vehicle paneling etc. [4] [5] [6] [7]. The Al-Mg alloys in liquid state had also been studied by theoreticians [8] [9] in the past. But these studies were only for a particular temperature; say $1073 \mathrm{~K}$ at which observed property is available. In present work, we have studied the thermodynamic, structural and transport properties of Al-Mg liquid alloys at different temperatures. These properties are then assessed by optimization procedure which is the thermodynamic description based on statistical thermodynamics or polynomial expressions.

There have been several studies based on the multiple theoretical models for the study of the mixing properties of liquid alloys [8]-[17]. In present work, we study the thermodynamic and structural properties of liquid Al-Mg alloys at different temperatures using regular associated solution model (RASM) [16] [17] [18] [19]. The surface tension of the alloy has been studied by Butler's model [20]. In previous works, we used RASM to study the properties of binary liquid alloys having complexes $A_{\mu} B_{v}$ with $\mu \geq 1$ and $v=1$ [16] [17] [18] [19] [21] [22]. The phase diagram of Al-Mg alloys [23] indicates that there exists an $\mathrm{Al}_{3} \mathrm{Mg}_{2}$ complex in the mixture. So we also assume the existence of the same complex in Al-Mg liquid alloys near melting temperature. Here $\mu=3$ and $v=2$. Thus the input parameters are obtained by using the expressions different from previous ones, which will be explained in section 2 of this article.

In RASM, the existence of complexes in binary solution is assumed and hence a binary alloy in molten state can be treated as a ternary mixture of monomers and complexes; all in chemical equilibrium [8] [16] [17] [19]. However, the interactions between both the unassociated atoms and the complex are not necessarily equal and therefore unassociated atoms may not interact equally with the complex [18] [19] [21] [22] [24]. The advantage of the RASM is that the most of the input parameters are computed by solving mathematical expressions [17] [18] [19] [24] [25] where as in most of the models the input parameters are estimated just by fitting methods.

The paper is organized as follows: In Section 2, the theoretical framework is presented. Section 3 gives the results and discussion of the work. Finally, the conclusions are outlined in Section 4.

\section{Formalism}

\subsection{Thermodynamic Properties}

We consider a mixture of $\mathrm{Al}$ and $\mathrm{Mg}$ metals in molten state which on the basis of RASM [16] [17] [18] [19] leads to a pseudo-ternary mixture of Al-Al, Mg- Mg monomers and $\mathrm{Al}_{\mu} \mathrm{Mg}_{v}$ complexes at equilibrium, where $\mu=3$ and $v=2$ [23]. On the basis of previous works [17] [18] [21] [25], it can be assumed that the thermodynamic properties of the liquid mixture is overruled by their true mole frac- 
tions $x_{\mathrm{A}}\left(=x_{\mathrm{Al}}\right), \quad x_{\mathrm{B}}\left(=x_{\mathrm{Mg}}\right)$ and $x_{\mathrm{Al}-\mathrm{Mg}}\left(=x_{\mathrm{A}-\mathrm{B}}\right)$ in spite of their gross fractions $C_{\mathrm{Al}}\left(=x_{1}\right)$ and $C_{\mathrm{Mg}}\left(=1-x_{1}=x_{2}\right)$. Relations between true mole fractions and gross mole fractions for $\mathrm{Al}-\mathrm{Mg}\left(=\mathrm{Al}_{\mu} \mathrm{Mg}_{v}\right)$ alloys at molten state can be developed using regular associated solution model and is given as

$$
\begin{aligned}
& x_{\mathrm{A}}=x_{1}\left[1+(\mu+v-1) x_{\mathrm{A}-\mathrm{B}}\right]-\mu x_{\mathrm{A}-\mathrm{B}} \\
& x_{\mathrm{B}}=x_{2}\left[1+(\mu+v-1) x_{\mathrm{A}-\mathrm{B}}\right]-v x_{\mathrm{A}-\mathrm{B}}
\end{aligned}
$$

On the basis of RASM, the expression of free energy of mixing, $\left(G_{\mathrm{M}}\right)$ can also be derived [16] [17] [18] [19] [24] [25] and is given as

$$
\begin{aligned}
G_{\mathrm{M}}= & \frac{1}{1+(\mu+v-1) x_{\mathrm{A}-\mathrm{B}}}\left[\left(x_{\mathrm{A}} x_{\mathrm{B}} \omega_{12}+x_{A} x_{\mathrm{A}-\mathrm{B}} \omega_{13}+x_{\mathrm{B}} x_{\mathrm{A}-\mathrm{B}} \omega_{23}\right)\right. \\
& \left.+R T\left(x_{\mathrm{A}} \ln x_{\mathrm{A}}+x_{\mathrm{B}} \ln x_{\mathrm{B}}+x_{\mathrm{A}-\mathrm{B}} \ln x_{\mathrm{A}-\mathrm{B}}\right)+x_{\mathrm{A}-\mathrm{B}} R T \ln k\right]
\end{aligned}
$$

where $\omega_{12}, \omega_{13}, \omega_{23}$ are respective interaction energy parameters between the pairs A, B; A, A-B and B, A-B respectively. $R$ is Universal gas constant, $T$ the temperature and $k$ the equilibrium constant to be estimated.

The equilibrium constant, $k$, is given as [16] [17] [25]

$$
k=\frac{x_{\mathrm{A}}^{\mu} x_{\mathrm{B}}^{v}}{x_{\mathrm{A}-\mathrm{B}}} \frac{\gamma_{\mathrm{A}}^{\mu} \gamma_{\mathrm{B}}^{v}}{\gamma_{\mathrm{A}-\mathrm{B}}}
$$

The activity coefficients $\gamma_{\mathrm{A}}$ for monomer $\mathrm{A}, \gamma_{\mathrm{B}}$ for monomer $\mathrm{B}$ and $\gamma_{\mathrm{A}-\mathrm{B}}$ for the complex A-B can be expressed in terms of true mole fractions and interaction energy parameters as [17] [24] [25]

$$
\begin{array}{r}
R T \ln \gamma_{\mathrm{A}}=x_{\mathrm{B}}^{2} \omega_{12}+x_{\mathrm{A}-\mathrm{B}}^{2} \omega_{13}+x_{\mathrm{B}} x_{\mathrm{A}-\mathrm{B}}\left(\omega_{12}-\omega_{23}+\omega_{13}\right) \\
R T \ln \gamma_{\mathrm{B}}=x_{\mathrm{A}-\mathrm{B}}^{2} \omega_{23}+x_{\mathrm{A}}^{2} \omega_{12}+x_{\mathrm{A}} x_{\mathrm{A}-\mathrm{B}}\left(\omega_{23}-\omega_{13}+\omega_{12}\right) \\
R T \ln \gamma_{\mathrm{A}-\mathrm{B}}=x_{\mathrm{A}}^{2} \omega_{13}+x_{\mathrm{B}}^{2} \omega_{23}+x_{\mathrm{A}} x_{\mathrm{B}}\left(\omega_{13}-\omega_{12}+\omega_{23}\right)
\end{array}
$$

The activity coefficients for pure components and monomers are connected by the relations [17] [26]

$$
x_{1} \gamma_{1}=x_{\mathrm{A}} \gamma_{\mathrm{A}} \text { and } x_{2} \gamma_{2}=x_{\mathrm{B}} \gamma_{\mathrm{B}}
$$

where $\gamma_{1}$ and $\gamma_{2}$ are gross activity coefficients of pure components $\mathrm{A}$ and $\mathrm{B}$ respectively.

The activity coefficients of monomers at infinite dilution can be related to the pairwise interaction energies by the following expressions [17]

$$
\begin{gathered}
\ln \gamma_{1}^{0}=\frac{\omega_{12}}{R T} \\
k \exp \left(\omega_{13} / R T\right)=\frac{\gamma_{1}^{0} \gamma_{2}^{0}}{\gamma_{1}^{0}-\gamma_{2}^{0}}
\end{gathered}
$$

where $\gamma_{1}^{0}$ and $\gamma_{2}^{0}$ are respective activity coefficients at zero dilutions.

On solving Equations (5a) and (5b) for $\frac{\omega_{13}}{R T}$ by substituting $x_{\mathrm{A}}+x_{\mathrm{B}}+x_{\mathrm{A}-\mathrm{B}}=1$, yields

$$
\frac{\omega_{13}}{R T}=\frac{x_{\mathrm{B}} \ln \left(\frac{a_{2}}{x_{\mathrm{B}}}\right)+\left(1-x_{\mathrm{B}}\right) \ln \left(\frac{a_{1}}{x_{\mathrm{A}}}\right)+x_{\mathrm{B}}\left(1-x_{\mathrm{B}}\right) \frac{\omega_{12}}{R T}}{x_{\mathrm{A}-\mathrm{B}}^{2}}
$$


Similarly, the expression for $\frac{\omega_{23}}{R T}$ can be obtained by solving Equations (5a) and (5b) as

$$
\frac{\omega_{23}}{R T}=\frac{x_{\mathrm{A}} \ln \left(\frac{a_{1}}{x_{\mathrm{A}}}\right)+\left(1-x_{\mathrm{A}}\right) \ln \left(\frac{a_{2}}{x_{\mathrm{B}}}\right)+x_{\mathrm{A}}\left(1-x_{\mathrm{A}}\right) \frac{\omega_{12}}{R T}}{x_{\mathrm{A}-\mathrm{B}}^{2}}
$$

where $a_{1}$ and $a_{2}$ are activities of the pure components $\mathrm{A}$ and $\mathrm{B}$ respectively.

The expression for the mole fraction of the complex in terms of interaction energies and activity of pure components of the alloy can be obtained by using Equation (9) in Equations (4) and (5) along with algebraic simplification as follows [17]

$$
\ln k+\frac{\omega_{13}}{R T}=\left(\frac{1+x_{\mathrm{A}}}{x_{\mathrm{A}-\mathrm{B}}}\right) \ln \left(\frac{a_{1}}{x_{\mathrm{A}}}\right)+\left(\frac{x_{\mathrm{B}}}{x_{\mathrm{A}-\mathrm{B}}}\right)\left[\ln \left(\frac{a_{2}}{x_{\mathrm{B}}}\right)-\frac{\omega_{12}}{R T}\right]+\ln \left(\frac{a_{1}^{\mu} a_{2}^{v}}{x_{\mathrm{A}-\mathrm{B}}}\right)
$$

The heat of mixing, $H_{\mathrm{M}}$ in terms of $G_{\mathrm{M}}$ is given by

$$
H_{\mathrm{M}}=G_{\mathrm{M}}-T\left(\frac{\partial G_{\mathrm{M}}}{\partial T}\right)_{P}
$$

Using Equations (3) and (11) we get

$$
\begin{aligned}
H_{\mathrm{M}}= & \frac{1}{1+(\mu+v-1) x_{\mathrm{A}-\mathrm{B}}}\left[\left(x_{\mathrm{A}} x_{\mathrm{B}} \omega_{12}+x_{\mathrm{A}} x_{\mathrm{A}-\mathrm{B}} \omega_{13}+x_{\mathrm{B}} x_{\mathrm{A}-\mathrm{B}} \omega_{23}\right)\right. \\
& \left.-T\left(x_{\mathrm{A}} x_{\mathrm{B}} \frac{\partial \omega_{12}}{\partial T}+x_{\mathrm{A}} x_{\mathrm{A}-\mathrm{B}} \frac{\partial \omega_{13}}{\partial T}+x_{\mathrm{B}} x_{\mathrm{A}-\mathrm{B}} \frac{\partial \omega_{23}}{\partial T}\right)+x_{\mathrm{A}-\mathrm{B}} R T^{2} \frac{\mathrm{d} \ln k}{\mathrm{~d} T}\right]
\end{aligned}
$$

where $\frac{\partial \omega_{12}}{\partial T}, \frac{\partial \omega_{13}}{\partial T}$ and $\frac{\partial \omega_{23}}{\partial T}$ are temperature derivatives of interaction energy parameters.

The entropy of mixing, $S_{\mathrm{M}}$ can be obtained by using standard thermodynamic relations

$$
S_{M}=\frac{H_{\mathrm{M}}-G_{\mathrm{M}}}{T}
$$

\subsection{Structural Properties}

The structural properties of the molten alloys can be assessed by means of concentration fluctuation in long wavelength limit $\left(S_{C C}(0)\right)$. The relation of $S_{C C}(0)$ with $G_{\mathrm{M}}$ given as [10]

$$
S_{C C}(0)=R T\left(\frac{\partial^{2} G_{\mathrm{M}}}{\partial^{2} x_{1}}\right)_{T, P}^{-1}
$$

Using Equation (3) in Equation (14) implying the constrains $\frac{\partial G_{\mathrm{M}}}{\partial x_{1}}=0$ for $\left(\frac{\partial^{2} G_{\mathrm{M}}}{\partial^{2} x_{1}}\right)>0$ and $\frac{\mathrm{d} \ln k}{\mathrm{~d} x_{1}}=0 \quad[18]$ yields 


$$
\begin{aligned}
S_{C C}(0)= & \left\{\frac { 1 } { 1 + ( \mu + v - 1 ) x _ { \mathrm { A } - \mathrm { B } } } \left[\frac{2}{R T}\left(x_{\mathrm{A}}^{\prime} x_{\mathrm{B}}^{\prime} \omega_{12}+x_{\mathrm{A}}^{\prime} x_{\mathrm{A} \mathrm{B}}^{\prime} \omega_{13}+x_{\mathrm{B}}^{\prime} x_{\mathrm{A}-\mathrm{B}}^{\prime} \omega_{23}\right)\right.\right. \\
& \left.\left.+\left(\frac{x_{\mathrm{A}}^{\prime 2}}{x_{\mathrm{A}}}+\frac{x_{\mathrm{B}}^{\prime 2}}{x_{\mathrm{B}}}+\frac{x_{\mathrm{A}-\mathrm{B}}^{\prime 2}}{x_{\mathrm{A}-\mathrm{B}}}\right)\right]\right\}
\end{aligned}
$$

where primes in true mole fractions denote the differentiations with concentrations. The observed value of the $S_{C C}(0)$ is obtained by the relations [10].

$$
S_{C C}(0)=\left(1-x_{1}\right) a_{1}\left(\frac{\partial a_{1}}{\partial x_{1}}\right)_{T, P}^{-1}=x_{1} a_{2}\left(\frac{\partial a_{2}}{\partial\left(1-x_{1}\right)}\right)_{T, P}^{-1}
$$

To measure the degree of ordering of binary alloys in liquid states, the knowledge of the Warren-Cowley [27] [28] short range order parameter $\left(\alpha_{1}\right)$ is essential. The $\alpha_{1}$ can be related to the $S_{C C}(0)$ by the relations [10] [11]

$$
\alpha_{1}=\frac{S-1}{S(Z)+1}, \text { with } S=\frac{S_{C C}(0)}{S_{C C}^{i d}(0)}
$$

where, $Z$ is the coordination number of the alloy and it is taken as 10 for our calculation. The value of $Z$ does not vary the nature of $\alpha_{1}$; the effect is to vary the depth not the overall features.

\subsection{Surface Properties}

If the bulk and hypothetical surface of a solution is assumed to be in equilibrium (Butler's approach [20]) the surface tension of a liquid solution can be expressed as [20] [29]

$$
\sigma=\frac{\mu_{1}^{s}-\mu_{1}^{b}}{\alpha_{1}}=\frac{\mu_{2}^{s}-\mu_{2}^{b}}{\alpha_{2}}=\cdots=\frac{\mu_{i}^{s}-\mu_{i}^{b}}{\alpha_{i}}
$$

where $\sigma, \mu_{i}^{s}, \mu_{i}^{b}$ and $\alpha_{i}$ are surface tension of the solution, chemical potential in the bulk and that in the hypothetical surface and molar surface area of ith component respectively. The chemical potential in the surface and in the bulk are related to the respective compositions and can be expressed by the same equation in the surface and in the bulk as follows [29]

$$
\mu_{i}^{s}=\mu_{i}^{s 0}+R T \ln x_{i}^{s}, \quad \mu_{i}^{b}=\mu_{i}^{b 0}+R T \ln x_{i}^{b}
$$

where $x_{i}^{s}$ and $x_{i}^{b}$ are the mole fraction of $i$ th component of the solution in the surface and that in the bulk respectively. For real solution the mole fraction is replaced by the activities because the activity coefficient is different from unity. Replacing the mole fractions by corresponding activities in Equation (19) and rearranging the equation, we get [20] [30]

$$
\sigma=\sigma_{1}+\frac{1}{\alpha_{1}}\left(G_{1}^{E, s}-G_{1}^{E, b}\right)+\frac{R T}{\alpha_{1}} \ln \left(\frac{x_{1}^{s}}{x_{1}^{b}}\right)=\sigma_{2}+\frac{1}{\alpha_{2}}\left(G_{2}^{E, s}-G_{2}^{E, b}\right)+\frac{R T}{\alpha_{2}} \ln \left(\frac{x_{2}^{s}}{x_{2}^{b}}\right)(20)
$$

where $G_{i}^{E, s}$ and $G_{i}^{E, b}$ are the partial excess free energy of mixing in the surface and that in the bulk. It may be proper to mention that $x_{1}^{s}+x_{2}^{s}=1$ and $x_{1}^{b}+x_{2}^{b}=1$. 
The molar surface area of a pure component $i$ in the liquid state can be expressed as [30]

$$
\alpha_{i}=f\left(V_{i}^{0}\right)^{2 / 3}(N)^{1 / 3}
$$

where $N$ is Avogadro's constant, $V_{i}^{0}$ is the molar volume of the pure component $i$ at its melting temperature and $f$ is the geometrical constant. The geometrical constant can be expressed as

$$
f=\left(\frac{3 f_{b}}{4}\right)^{2 / 3} \frac{\pi^{1 / 3}}{f_{2}}
$$

where $f_{b}$ is the volume packing fraction and $f_{s}$ is the surface packing fraction. Their values depend upon the type of crystal structure of the pure components of the alloys.

\subsection{Optimization Procedure Thermodynamic, Structural and Surface Properties}

A consistent set of model parameters in an analytical approach can be obtained by the optimization procedure which is the thermodynamic description based on statistical thermodynamics or polynomial expressions. The adjustable coefficients, used in the process, are estimated by least square method which gives an idea to extrapolate into temperature and concentration region in which the direct observed determination is unavailable.

The various thermodynamic properties, described by a power-series law whose coefficient are $A, B, C, D, E \ldots$ (say), are determined by least-square method [31]. The heat capacity can be expressed as

$$
C_{P}=-C-2 D T-2 E T^{-2}
$$

From the thermodynamic relation, the heat of mixing and entropy of mixing are given by

$$
\begin{gathered}
H=H\left(T_{0}\right)+\int_{0}^{T} C_{P} \mathrm{~d} T=A-C T-D T^{2}+2 E T^{-1}-\cdots \\
S=S\left(T_{0}\right)+\int_{0}^{T} \frac{C_{P}}{T} \mathrm{~d} T=-B-C(1+\ln T)-2 D T+E T^{-2}-\cdots
\end{gathered}
$$

Using Equations (24) and (25) in the thermodynamic relation, $G_{M}=H-T S$, we get the temperature $(T)$ dependent free energy as

$$
G=A+B T+C T \ln T+D T^{2}+E T^{-1}+\cdots
$$

Redlich-Kister polynomial equation gives the composition dependence of excess free energy of mixing and is given by

$$
G_{M}^{X S}(c, T)=c(1-c) \sum_{l=0}^{m} K_{l}(T)[c-(1-c)]^{l}
$$

with

$$
K_{l}(T)=A_{l}+B_{l} T+C_{l} T \ln T+D_{l} T^{2}+\cdots
$$

The coefficients $K_{1}$ is the function of the temperature same as that of $G$ in Eq- 
uation (26). The least-square method can be used to obtain the parameters involved in Equation (26). For this purpose, we calculate the excess free energy of mixing $\left(G_{M}^{X S}\right)$ of the Al-Mg liquid alloy at different temperatures by the relation

$$
G_{M}^{X S}=G_{M}-G_{M}^{i d}
$$

\section{Results and Discussion}

\subsection{Thermodynamic, Structural and Surface Properties at $1073 \mathrm{~K}$}

\subsubsection{Thermodynamic Properties}

The input parameter $\frac{\omega_{12}}{R T}$ was computed from the Equation (7) using activity coefficient of $\mathrm{Al}$ at zero dilution. The mole fractions of the complex $x_{\mathrm{Al}-\mathrm{Mg}}$ and the unassociated components $x_{\mathrm{Al}}, x_{\mathrm{Mg}}$ were estimated by using Equations (7) and (8) in (10) with the knowledge of observed activities [23] of pure components of Al-Mg alloy in liquid state at $1073 \mathrm{~K}$. The compositional dependence of mole fractions (Figure 1) shows that the maximum association between the components of the alloy occurs at $C_{\mathrm{Al}}=0.6$ which is compound forming concentration $\left(=\frac{\mu}{v+v}=\frac{3}{2+3}=0.6\right)$. At this concentration, about $16.1 \%$ of the alloy is associated. The other model parameters $\frac{\omega_{13}}{R T}$ and $\frac{\omega_{23}}{R T}$ were estimated by using Equations (9a) and (9b). These estimated values were slightly adjusted to explain the observed values of free energy of mixing at all concentrations [23]. The pairwise interaction energy parameters and equilibrium constant for $\mathrm{Al}-\mathrm{Mg}$ alloys in liquid state at $1073 \mathrm{~K}$ were found as

$$
\begin{aligned}
& \omega_{12}=-6253.57 \mathrm{~J} \cdot \mathrm{mol}^{-1}, \omega_{13}=+30687.97 \mathrm{~J} \cdot \mathrm{mol}^{-1}, \\
& \omega_{23}=+16682.18 \mathrm{~J} \cdot \mathrm{mol}^{-1} \text { and } k=0.055
\end{aligned}
$$

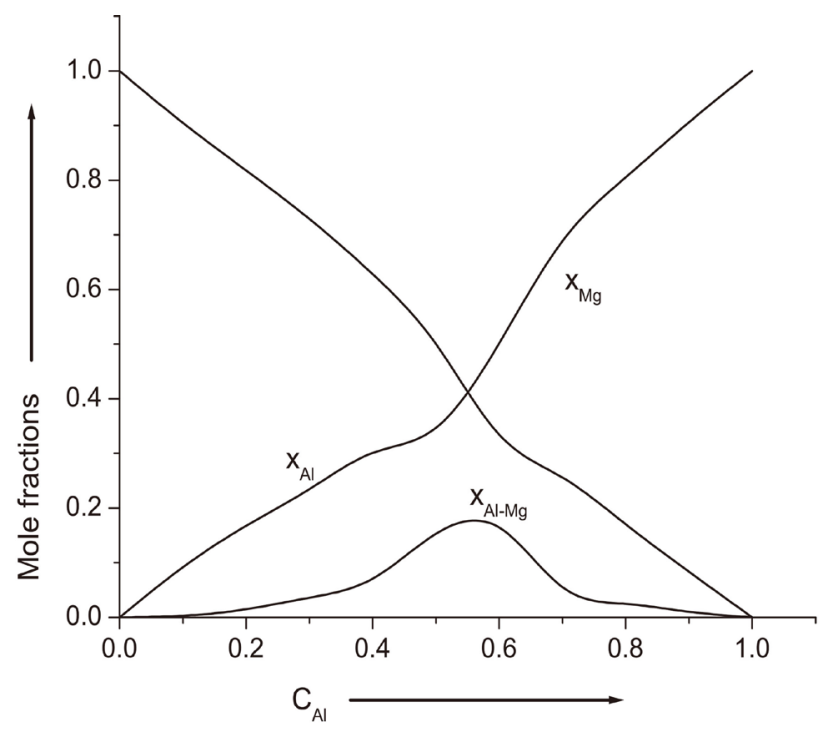

Figure 1. Compositional dependence of mole fractions of Al-Mg alloy in liquid state at $1073 \mathrm{~K}$. 
The negative value of $\omega_{12}$ shows that $\mathrm{Al}$ and $\mathrm{Mg}$ atoms in the liquid alloy are attracted to each other. Similarly, the positive value of $\omega_{13}$ and $\omega_{23}$ show that there is repulsion between $\mathrm{Al}$ atoms and the complexes $\mathrm{Al}-\mathrm{Mg}$ and $\mathrm{Mg}$ atoms and the complexes Al-Mg respectively.

The free energy of mixing was computed from Equation (3) by using aforementioned model parameters. There is good agreement between the computed and observed value of free energy of mixing (Figure 2). It has been observed that both the computed and observed values of free energy of mixing are minimum at equiatomic composition $\left(C_{\mathrm{Al}}=0.5\right)$. Moreover, the computed values of excess free energy of mixing at equiatomic composition and temperature $(=-0.2778 R T)$ indicates that the system is moderately interacting and hence the affinity towards the compound formation is moderate.

On using Equation (12) and observed heat of mixing [23] the optimized value of the following parameters were found as

$$
\begin{aligned}
& \frac{\partial \omega_{12}}{\partial T}=+5.44 \mathrm{~J} \cdot \mathrm{mol}^{-1} \cdot \mathrm{K}^{-1}, \frac{\partial \omega_{13}}{\partial T}=+23.00 \mathrm{~J} \cdot \mathrm{mol}^{-1} \cdot \mathrm{K}^{-1}, \\
& \frac{\partial \omega_{23}}{\partial T}=+9.67 \mathrm{~J} \cdot \mathrm{mol}^{-1} \cdot \mathrm{K}^{-1} \text { and } R T^{2} \frac{\mathrm{d} \ln k}{\mathrm{~d} T}=30000 \pm 1850 \mathrm{~J} \cdot \mathrm{mol}^{-1}
\end{aligned}
$$

The need of aforementioned temperature derivative terms of interaction energy parameters to explain the observed heat of mixing clearly indicates that the pairwise interaction energy parameters are strongly dependent on temperature. There is good agreement between the computed and observed values of heat of mixing at all concentration except at or about equiatomic composition (Figure 3). Both the computed and observed values of heat of mixing are minimum at $C_{\mathrm{Al}}=0.54$. At this composition, the computed value of $\frac{H_{\mathrm{M}}}{R T}$ is $-0.4053 R T$ where as the corresponding observed values is $-0.3814 R T$ [23]. This low negative value suggests that the bonding between the species $\mathrm{Al}$ and $\mathrm{Mg}$ to form the complex is weak. The entropy of mixing for the alloys was also computed using Equation (13). Both the computed and observed values of entropy of mixing were found to be in good agreement (Figure 3).

The activities of the components of the alloys were computed from Equations (5) and (6) using the same input parameters which were used for the computation of free energy of mixing, heat of mixing and entropy of mixing. The computed and observed values [23] were found to be in good agreement (Figure 4). The parameter, activity assesses the deviation of the system from the ideal behavior. Thus the knowledge of activities within a class of identical structure can be expected to offer, at least, a basis for correlation of the behaviour, which can then be used for extrapolation of the behaviour of a more complex system.

\subsubsection{Structural Properties}

The $S_{C C}(0)$ can be used to study the structural properties of the alloy at microscopic level [10]. The mixing and phase separation behavior in the binary liquid alloys can be predicted with the knowledge of the $S_{C C}(0)$. In general for 
a liquid binary alloy, when the computed $S_{C C}(0)$ is greater than the ideal value, i.e. $S_{C C}(0)>S_{C C}^{i d}$, there is homo-coordination or like atoms pairing in the alloy [10]. When $S_{C C}(0)<S_{C C}^{i d}$, there is hetero-coordination or unlike atoms pairing and when $S_{C C}(0)=S_{C C}^{i d}$, there is an ideal mixing of components [10]. The $S_{C C}(0)$ was computed by using Equations (15) and (16). Both the computed and the observed values of the $S_{C C}(0)$ are greater than the ideal values at all concentrations (Figure 5). This indicates that $\mathrm{Al}-\mathrm{Mg}$ alloys in liquid state at $1073 \mathrm{~K}$ is ordering in nature at whole compositions.

The structural behaviour of the molten alloy can further be understood in terms of the Warren-Cowley short-range order parameter $\left(\alpha_{1}\right)$. The relative strength of the local order of atoms in the molten alloy is expressed in terms of

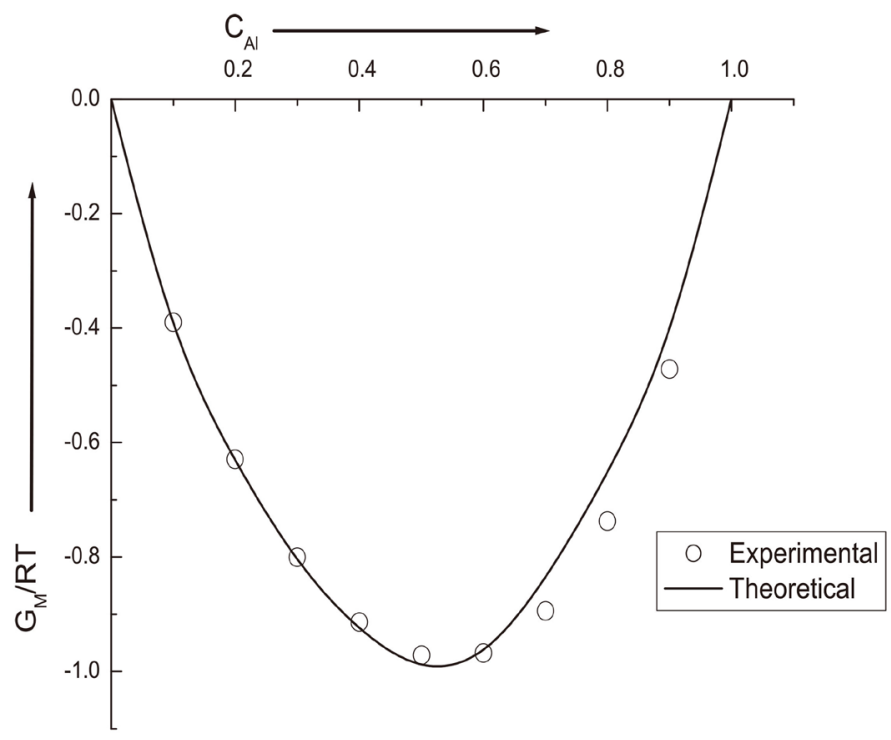

Figure 2. Compositional dependence of $\left(G_{\mathrm{M}} / R T\right)_{\mathrm{Exp}}$ and $\left(G_{\mathrm{M}} / R T\right)_{\mathrm{Th}}$ of Al-Mg liquid alloy at $1073 \mathrm{~K}$.

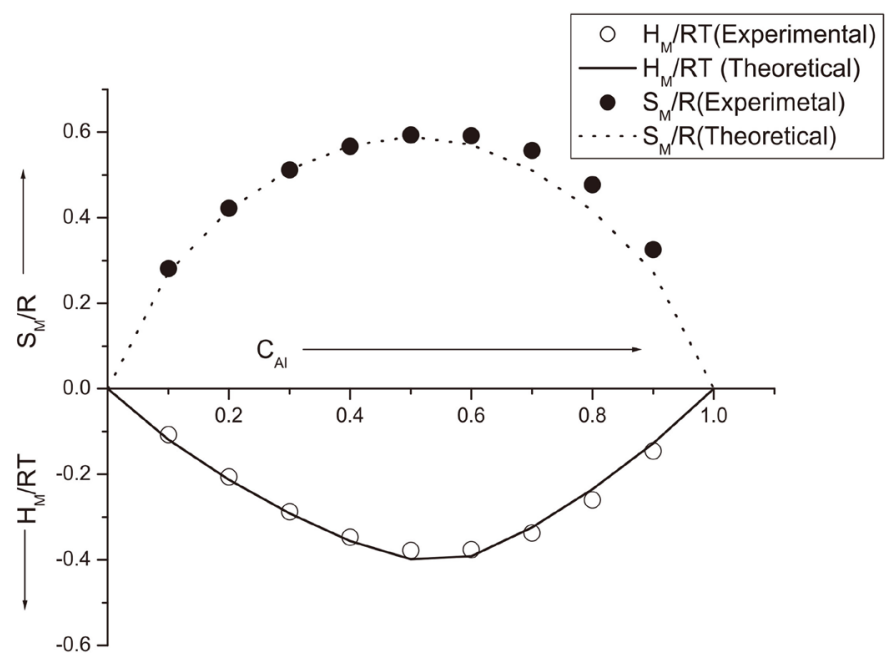

Figure 3. Compositional dependence of $\left(H_{\mathrm{M}} / R T\right)_{\mathrm{Exp}},\left(H_{\mathrm{M}} / R T\right)_{\mathrm{Th}}$ and $\left(S_{\mathrm{M}} / R\right)_{\mathrm{Exp}},\left(S_{\mathrm{M}} / R\right)_{\mathrm{Th}}$ of Al-Mg liquid alloy at $1073 \mathrm{~K}$. 


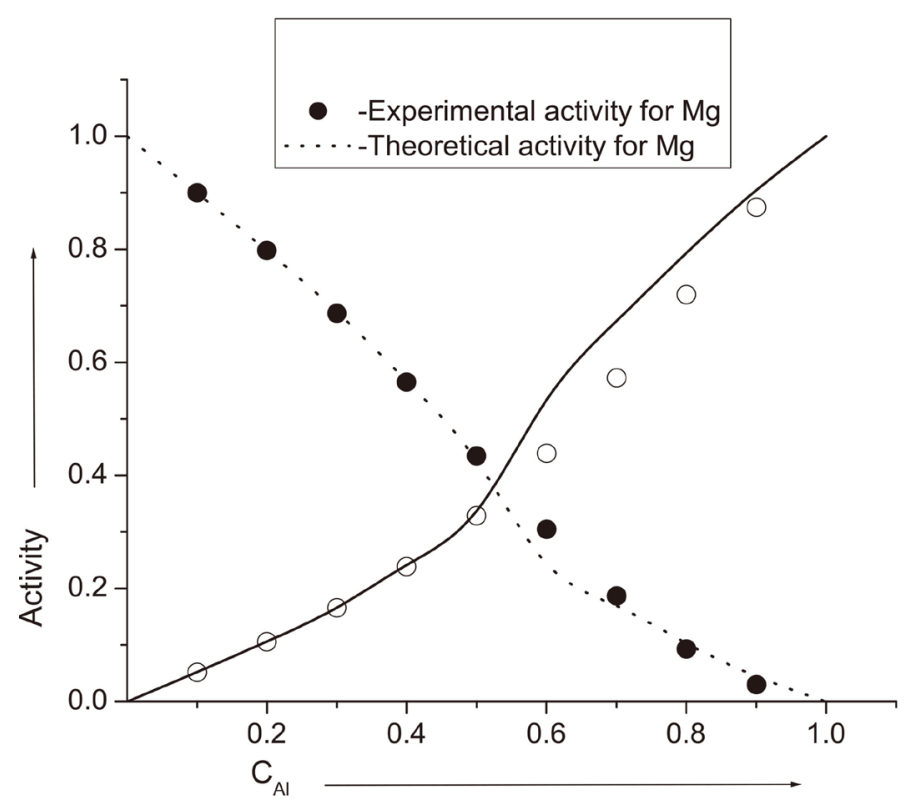

Figure 4. Compositional dependence of activity of Al-Mg liquid alloy at $1073 \mathrm{~K}$.

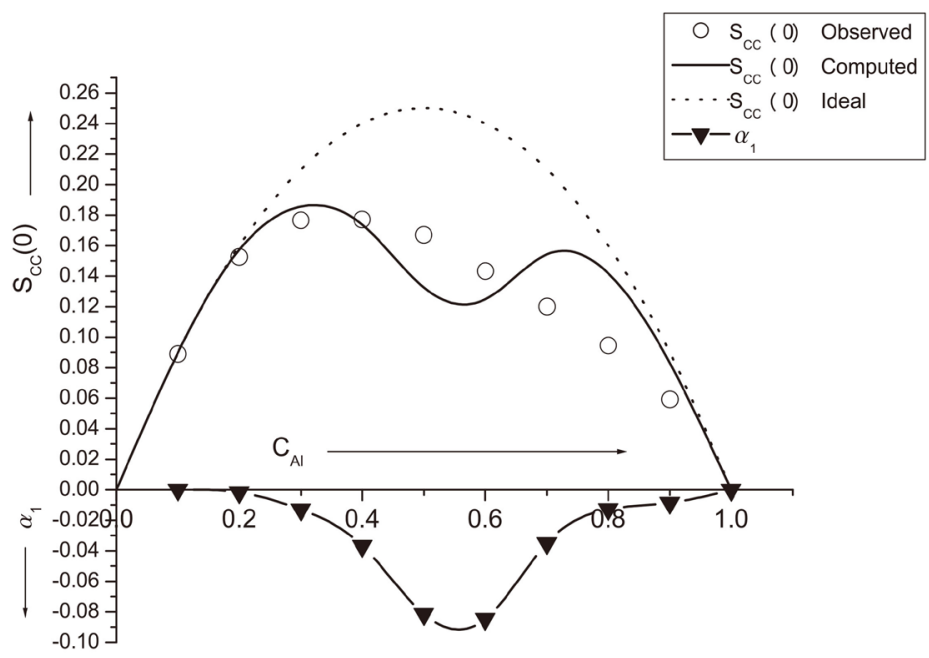

Figure 5. Compositional dependence of $\left(S_{c c}(0)\right)_{\text {observed }},\left(S_{c c}(0)\right)_{\text {computed, }}$ $\left(S_{c c}(0)\right)_{\text {ideal }}$ and $\alpha_{1}$ of Al-Mg liquid alloy at $1073 \mathrm{~K}$.

normalized values of this parameter. The normalized value of the $\alpha_{1}$ lies between -1 and +1 . The positive values of $\alpha_{1}$ indicate the phase separation (segregating); whereas the negative values of $\alpha_{1}$ indicate the ordering (compound forming) in the binary liquid alloys. The value of $\alpha_{1}$ is computed from Equation (17) and plotted in Figure 5. The $\alpha_{1}$ was found negative at all compositions which indicates that $\mathrm{Al}-\mathrm{Mg}$ alloys in liquid state at $1073 \mathrm{~K}$ is compound forming alloys in all compositions.

\subsubsection{Surface Properties}

The surface tension of the alloys in liquid state at $1073 \mathrm{~K}$ was calculated by using 
Equation (20). For this, the properties, such as densities, surface tensions and partial excess free energies of the component metals at temperature of investigation are required. Densities $\left(\rho_{i}(T)\right)$ and surface tensions $\left(\sigma_{i}(T)\right)$ of the components $\mathrm{Al}$ and $\mathrm{Mg}$ metals at $1073 \mathrm{~K}$ were calculated from their values at respective melting temperatures using the following relations [32]

$$
\begin{gathered}
\rho_{\mathrm{Al}}(T)=2345-0.2800 \times\left(T-T_{\mathrm{Al}, 0}\right), \\
\rho_{\mathrm{Mg}}(T)=1590-0.2647 \times\left(T-T_{\mathrm{Mg}, 0}\right)\left(\mathrm{kg} \cdot \mathrm{m}^{-3}\right), \\
\sigma_{\mathrm{Al}}(T)=0.914-0.35 \times 10^{-3}\left(T-T_{\mathrm{Al}, 0}\right), \\
\sigma_{\mathrm{Mg}}(T)=0.559-0.35 \times 10^{-3}\left(T-T_{\mathrm{Mg}, 0}\right)\left(\mathrm{N} \cdot \mathrm{m}^{-1}\right)
\end{gathered}
$$

where $T_{\mathrm{Al}, 0}=933 \mathrm{~K}, T_{\mathrm{Mg}, 0}=924 \mathrm{~K}$ and $T=1073 \mathrm{~K}$.

The bulk partial excess free energy of mixing for the individual components of the alloys in liquid state at $1073 \mathrm{~K}$ is available in [23]. We considered the geometrical constant $f=1.061$ [30] and $\beta=\frac{G_{i}^{E, S}}{G_{i}^{E, B}}=0.8181$ [30]. The computed values of surface concentrations for the components and surface tension of the solution were computed and plotted in Figure 6 and Figure 7 respectively. The surface concentration of $\mathrm{Al}$ is less than ideal values whereas that of $\mathrm{Mg}$ atoms is greater than ideal values at all compositions indicating that the former atoms remains in the bulk whereas later segregate on the surface of the solution at melting temperature. Figure 7 shows that the surface tension of the solution is found to be less than ideal value in the entire range of concentrations at $1073 \mathrm{~K}$.

\subsection{Thermodynamic, Structural and Surface Properties at $T \geq 1073 \mathrm{~K}$}

In order to calculate the thermodynamic, structural and surface properties of alloys in liquid state at different temperatures we have made the following assumptions:

1) True mole fractions of the monomers and that of complex are temperature independent.

2) The pairwise interaction energies are temperature dependent.

3) The temperature dependence of pairwise interaction energies is linear above melting temperature.

Under these assumptions, the variation of interaction energy parameters with temperature can be expressed as

$$
\mathrm{d}\left[\omega_{i j}(T)\right]_{C}=\frac{\partial \omega_{i j}(T)}{\partial T} \mathrm{~d} T
$$

where $i, j=1,2,3 ; i \neq j . C$ is the mole fraction.

$$
\omega_{i j}\left(T_{K}\right)=\omega_{i j}(T)+\frac{\partial \omega_{i j}(T)}{\partial T} \mathrm{~d} T
$$

where, $\mathrm{d} T=T_{k}-T ; T_{k}=1173 \mathrm{~K}, 1273 \mathrm{~K}, 1373 \mathrm{~K}$. 


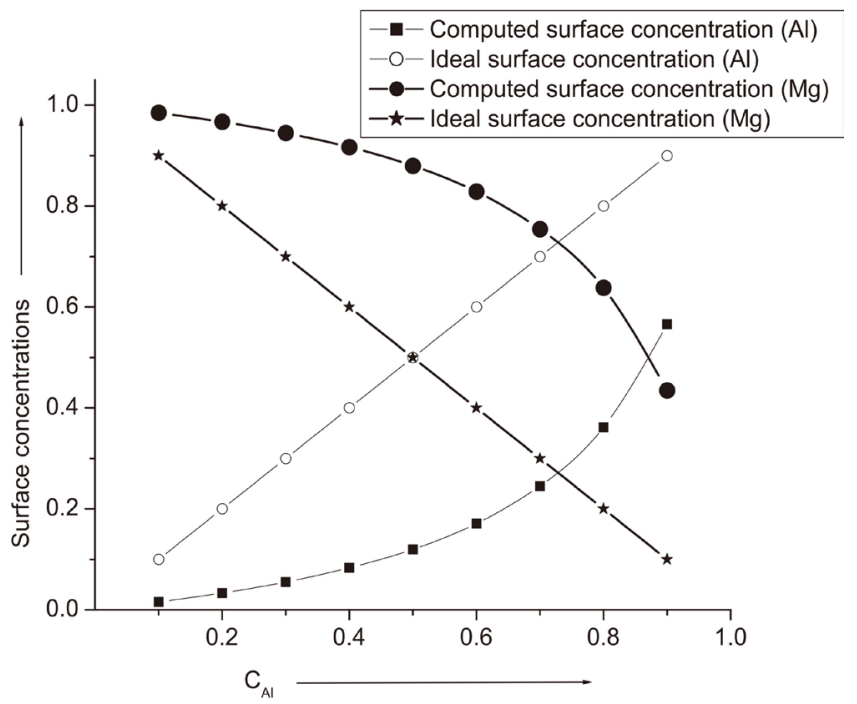

Figure 6. Compositional dependence of computed values of surface concentrations for the components of $\mathrm{Al}-\mathrm{Mg}$ liquid alloy at $1073 \mathrm{~K}$.

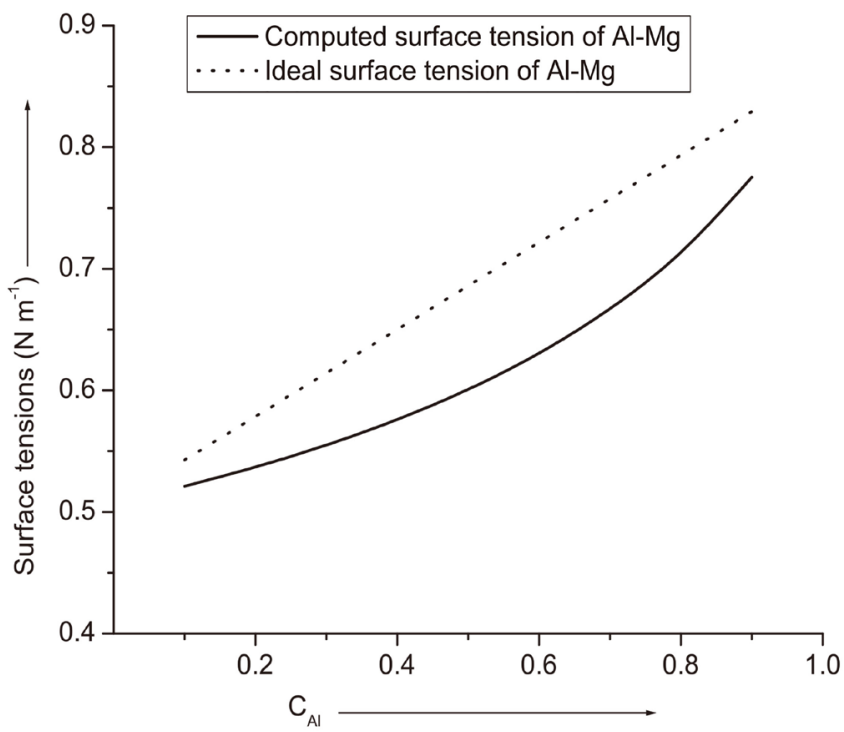

Figure 7. Compositional dependence of computed values of surface tension of $\mathrm{Al}-\mathrm{Mg}$ liquid alloy at $1073 \mathrm{~K}$.

Now the values of pairwise interaction energy parameters at $1073 \mathrm{~K}$ and their temperature derivatives were used in Equation (31) to obtain the pairwise interaction energy parameters at temperatures $1173 \mathrm{~K}, 1273 \mathrm{~K}$ and $1373 \mathrm{~K}$. These input parameters were used in Equation (3) to estimate the free energy of mixing of the alloys at different temperatures. The computed values of free energy of mixing were then used to compute corresponding excess free energy of mixing using Equation (29). The model parameters for the prediction of thermodynamic properties of the alloys at any temperature were computed using Equations (27) and (28) optimization procedure (Table 1). The optimized values of free energy of mixing for Al-Mg alloys at different temperatures are plotted in Figure 
8. The plot clearly shows that the free energy of mixing becomes smaller in magnitudes as the temperature increases. Thus the ordering behavior of the alloys will be weaker and weaker as the temperature increases.

The optimized value of partial excess free energy of mixing of the constituent $X(\equiv \mathrm{Al})$ and $Y(\equiv \mathrm{Mg})$ in $\mathrm{Al}-\mathrm{Mg}$ liquid alloys are respectively given by

$$
\tilde{G}_{M, X}^{X S}(c, T)=(1-c)^{2} \sum_{l=0}^{m} K_{l}(T)[2 c(l+1)-1](2 c-1)^{l-1}
$$

and

$$
\tilde{G}_{M, Y}^{X S}(c, T)=c^{2} \sum_{l=0}^{m} K_{l}(T)[2 c(l+1)-2 l-1](2 c-1)^{l-1}
$$

The activity coefficients of the components of the alloys at different temperatures were computed by the relations

$$
\tilde{G}_{M, i}^{X S}(c, T)=R T \ln \gamma_{i}
$$

where $i=\mathrm{Al}, \mathrm{Mg}$.

The activities of the components of the alloys at different temperatures were then computed by using the calculated values of the corresponding activity coefficients and plotted in Figure 9.

We computed the $S_{C C}(0)$ at different temperatures and plotted in Figure 10. The $S_{C C}(0)$ shifts towards the ideal values as the temperature increases. For concentrations $C_{\mathrm{Al}}=0.1-0.2$, the $S_{C C}(0)$ crosses the ideal values at $T \geq 1173 \mathrm{~K}$. This is a usual variation of the $S_{C C}(0)$ with temperature.

The values of the partial excess free energy of mixing computed from Equations (32) and (33) at required temperatures are fortune input parameters to calculate the surface tension of the liquid alloy at higher temperatures. The surface tension and hence the surface concentration of $\mathrm{Al}$ and $\mathrm{Mg}$ atoms of the system at temperatures 1173, 1273 and $1373 \mathrm{~K}$ are obtained from Equation (20) following the similar procedure as that for temperature $1073 \mathrm{~K}$. The compositional and temperature dependence of the surface tension of the liquid Al-Mg alloy at higher temperatures is shown (Figure 11). It can be observed that the surface tension of the liquid alloy decreases with the increase in its temperature. The surface concentration of $\mathrm{Al}$ of the liquid alloy increases with increase in its temperature (Figure 12). The surface concentrations of $\mathrm{Mg}$ atoms of the liquid alloy decreases with the increase in its temperature. This indicates that the atoms in the bulk tend to segregate and the atoms in the surface tend to move to the bulk as the temperature increases.

Table 1. Calculated values of optimized coefficients $A_{b} B_{b} C_{l}$ and $D_{l}(I=0$ to 3$)$ in liquid alloy Al-Mg.

\begin{tabular}{ccccc}
\hline$I$ & $A_{l}\left(\mathrm{~J} \cdot \mathrm{mol}^{-1}\right)$ & $B_{l}\left(\mathrm{~J} \cdot \mathrm{mol}^{-1} \cdot \mathrm{K}^{-1}\right)$ & $C_{l}\left(\mathrm{~J} \cdot \mathrm{mol}^{-1} \cdot \mathrm{K}^{-1}\right)$ & $D_{l}\left(\mathrm{~J} \cdot \mathrm{mol}^{-1} \cdot \mathrm{K}^{-2}\right)$ \\
\hline 0 & $-9.551 \times 10^{5}$ & $1.067 \times 10^{4}$ & $-1.494 \times 10^{3}$ & 0.590063 \\
1 & $-2.620 \times 10^{6}$ & $2.988 \times 10^{4}$ & $-4.189 \times 10^{3}$ & 1.670447 \\
2 & $-2.357 \times 10^{6}$ & $2.740 \times 10^{4}$ & $-3.852 \times 10^{3}$ & 1.567968 \\
3 & $-7.793 \times 10^{5}$ & $9.349 \times 10^{3}$ & $-1.320 \times 10^{3}$ & 0.555166 \\
\hline
\end{tabular}




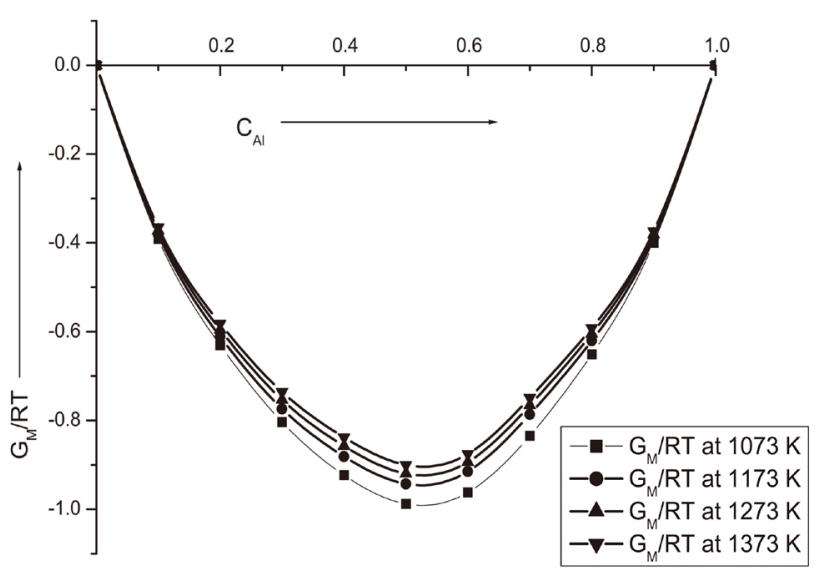

Figure 8. Compositional dependence of $G_{\mathrm{M}} / R T$ of Al-Mg liquid alloy at different temperatures.

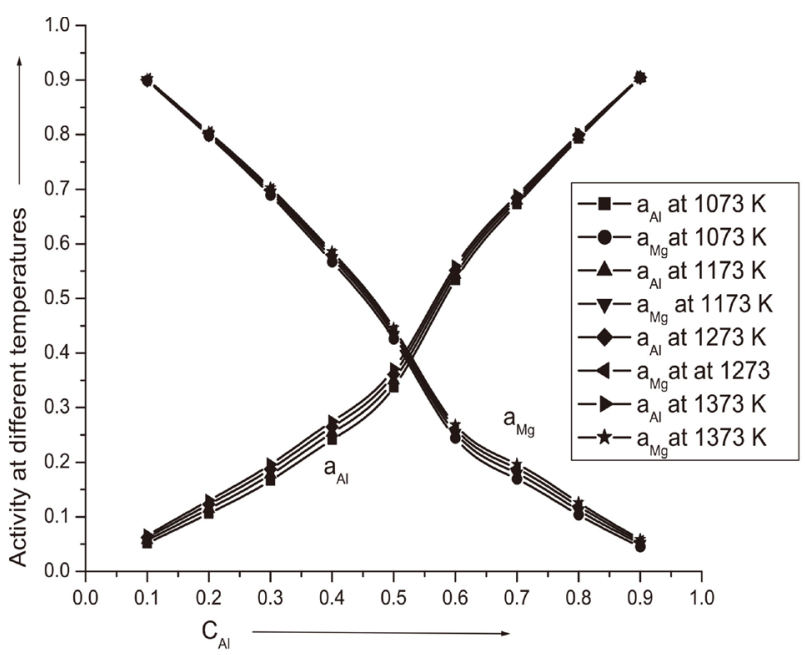

Figure 9. Compositional dependence of activity of Al-Mg liquid alloy at different temperatures.

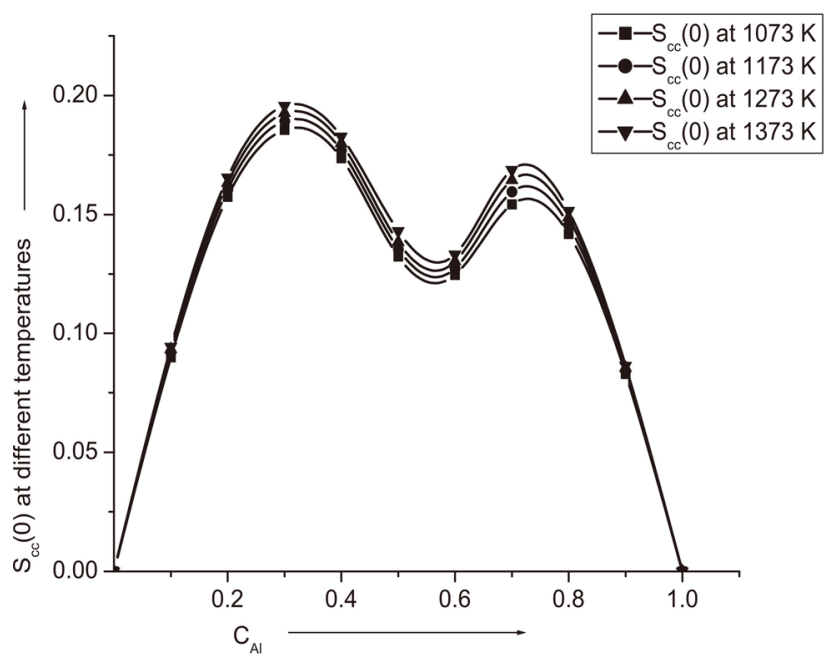

Figure 10. Compositional dependence $S_{c c}(0)$ of Al-Mg liquid alloy at different temperatures. 


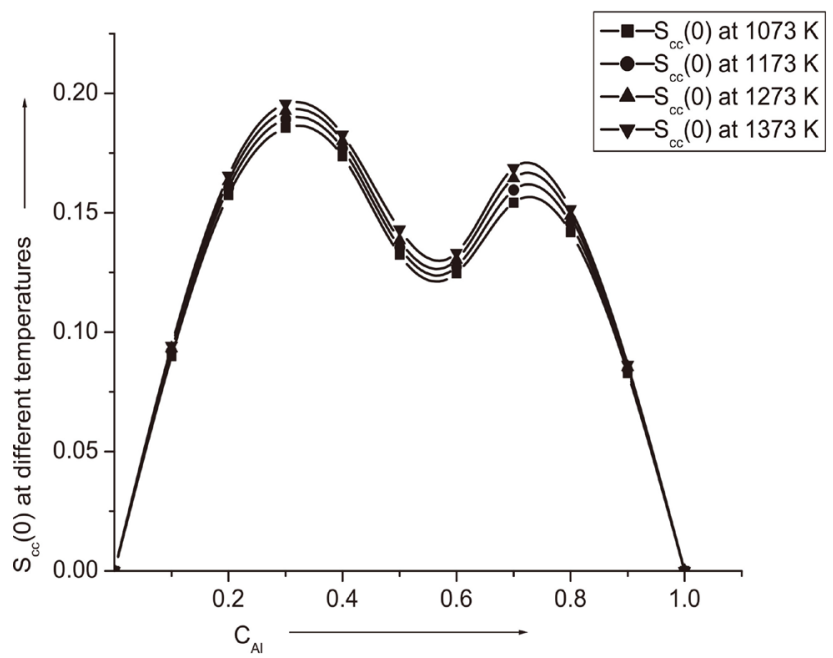

Figure 11. Compositional dependence of surface tensions of $\mathrm{Al}-\mathrm{Mg}$ liquid alloy at different temperatures.

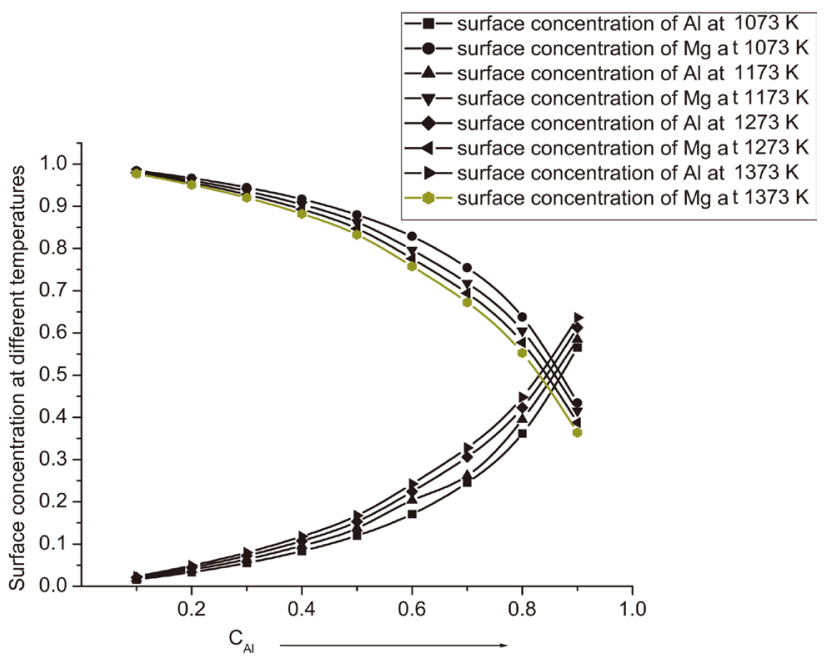

Figure 12. Compositional dependence of surface concentration of $\mathrm{Al}-\mathrm{Mg}$ liquid alloy at different temperatures.

\section{Conclusions}

From our study the following conclusions can be drawn:

1) The Al-Mg liquid alloy is moderately interaction in nature.

2) The Al-Mg liquid alloy is ordering alloy at $1073 \mathrm{~K}$. Above this temperature the nature of the alloy shifts towards the ideal nature.

3) $\mathrm{Al}$ atoms remain in the bulk and $\mathrm{Mg}$ atoms segregate in the surface.

4) The surface tension of the alloy is lesser than ideal values at all temperatures.

\section{Acknowledgements}

The authors are thankful to University Grants Commission, Nepal for providing funds to pursue research work under Faculty Research Grant scheme (FRG-73/74-S\&T-14). 


\section{Conflicts of Interest}

The authors declare no conflicts of interest regarding the publication of this paper.

\section{References}

[1] Kaushik, Y. (2015) A Review on Use of Aluminium Alloys in Aircraft Components. I-Manager's Journal on Material Science, 3, 33-38

[2] Sah, S., Bawase, M. and Saraf, M. (2014) Light-Weight Materials and Their Automotive Applications. SAE Technical Paper 2014-28-0025.

[3] Gao, L.X., Wang, L.N., Qi, T., et al. (2008) Electrodeposition of Aluminum from $\mathrm{AlCl}_{3} / \mathrm{Et}_{3} \mathrm{NHCl}$ Ionic Liquids. Acta Physico-Chimica Sinica, 24, 939-944.

https://doi.org/10.1016/S1872-1508(08)60040-6

[4] Król, M., Tański, T., Snopiński, P. and Tomiczek, B. (2017) Structure and Properties of Aluminium-Magnesium Casting Alloys after Heat Treatment. Journal of Thermal Analysis and Calorimetry, 127, 299-308. https://doi.org/10.1007/s10973-016-5845-4

[5] Schoenitz, M. and Dreizin, E.L. (2003) Structure and Properties of Al-Mg Mechanical Alloys. Journal of Materials Research, 18, 1827-1836. https://doi.org/10.1557/JMR.2003.0255

[6] Scudino, S., Sakaliyska, M., Surreddi, K.B., Ali, F. and Eckert, J. (2010) Structure and Mechanical Properties of Al-Mg Alloys Produced by Copper Mold Casting. Journal of Alloys and Compounds, 504, S483-S486.

https://doi.org/10.1016/j.jallcom.2010.03.208

[7] Jiang, D.M, Kang, S.B. and Kim, H.W. (2010) Microstructure and Mechanical Properties of Al-Mg Alloy Sheets for Auto-Body Application. Materials Science and Technology, 15, 1401-1407. https://doi.org/10.1179/026708399101505536

[8] Prasad, L.C., Chatterjee, S.K. and Singh, V.N. (1996) Intermetallic Associations in AlMg Liquid Alloys. Physica B: Condensed Matter, 217, 285-291. https://doi.org/10.1016/0921-4526(95)00885-3

[9] Adhikari, D., Jha, I.S. and Singh, B.P. (2012) Mixing Properties of Al-Mg Liquid Alloys. Indian Journal of Physics, 86, 783-786. https://doi.org/10.1007/s12648-012-0113-3

[10] Bhatia, A.B. and Hargrove, W.H. (1974) Concentration Fluctuation and Thermodynamic Properties of Some Compound Forming Binary Molten Alloys. Physical Review B, 10, 3186-3196. https://doi.org/10.1103/PhysRevB.10.3186

[11] Bhatia, A.B. and Singh, R.N. (1982) Short Range Order and Concentration Fluctuations in Regular and Compound Forming Molten Alloys. Physics and Chemistry of Liquids, 11, 285-313. https://doi.org/10.1080/00319108208080752

[12] Novakovic, R., Muolo, M.L. and Passerone, A. (2004) Bulk and Surface Properties of Liquid X-Zr (X=Ag, Cu) Compound Forming Alloys. Surface Science, 549, 281-293. https://doi.org/10.1016/j.susc.2003.12.006

[13] Sommer, F. (1990) Thermodynamic Properties of Compound-Forming Liquid Alloys. Journal of Non-Crystalline Solids, 117-118, 505-512. https://doi.org/10.1016/0022-3093(90)90580-F

[14] Jha, N. and Mishra, A.K. (2001) Thermodynamic and Surface Properties of Liquid Mg-Zn Alloys. Journal of Alloys and Compounds, 329, 224-229. https://doi.org/10.1016/S0925-8388(01)01684-X

[15] Koirala, R.P., Kumar, J., Singh, B.P. and Adhikari, D. (2014) Bulk and Surface 
Properties of Co-Fe and Fe-Pd Liquid Alloys. Journal of Non-Crystalline Solid, 394-395, 9-15. https://doi.org/10.1016/j.jnoncrysol.2014.04.001

[16] Jordan, A.S. (1970) A Theory of Regular Associated Solution Applied to the Liquidus Curves of the Zn-Te and Cd-Te System. Metallurgical Transactions, 1, 239-249.

[17] Lele, S. and Ramchandrarao, P. (1981) Estimation of Complex Concentration in a Regular Associated Solution. Metallurgical Transactions B, 12, 659-666. https://doi.org/10.1007/BF02654134

[18] Adhikari, D., Jha, I.S. and Singh, B.P. (2010) Structural Asymmetry in Liquid Fe-Si Alloys. Philosophical Magazine, 90, 2687-2694.

https://doi.org/10.1080/14786431003745302

[19] Yadav, S.K., Jha, L.N. and Adhikari, D. (2015) Thermodynamic and Structural Properties of Bi-Based Liquid Alloys. Physica B, 475, 40-47.

https://doi.org/10.1016/j.physb.2015.06.015

[20] Butler, J.A.V. (1932) The Thermodynamics of the Surfaces of the Solutions. Proceedings of Royal Society A: Mathematical, Physical and Engineering Science, 135, 348-375. https://doi.org/10.1098/rspa.1932.0040

[21] Adhikari, D., Singh, B.P., Jha, I.S. and Singh, B.K. (2010) Thermodynamic Properties and Microscopic Structure of Liquid Cd-Na Alloys by Estimating Complex Concentration in a Regular Associated Solution. Journal of Molecular Liquids, 156, 115-119. https://doi.org/10.1016/j.molliq.2010.05.020

[22] Adhikari, D., Singh, B.P., Jha, I.S. and Singh, B.K. (2011) Chemical Ordering and Thermodynamic Properties of HgNa Liquid Alloys. Journal of Non-Crystalline Solids, 357, 2892-2896. https://doi.org/10.1016/j.jnoncrysol.2011.03.029

[23] Hultgren, R., Desai, P.D., Hawkins, D.T., Gleiser, M. and Kelley, K.K. (1973) Selected Values of the Thermodynamic Properties of Binary Alloys, ASM, Metal Park.

[24] Yadav, S.K., Jha, L.N., Jha, I.S., Singh, B.P., Koirala, R.P. and Adhikari, D. (2016) Prediction of Thermodynamic and Surface Properties of $\mathrm{Pb}-\mathrm{Hg}$ Liquid Alloys at Different Temperatures. Philosophical Magazine, 96, 1909-1925. https://doi.org/10.1080/14786435.2016.1181281

[25] Srikanth, S. and Jacob, K.T. (1988) Volume Effect and Associations in Liquid Alloys. Metallurgical Transactions B, 19, 465-470. https://doi.org/10.1007/BF02657745

[26] Osamura, K. and Predal, B. (1977) Association in Metallic Solution. Transactions of the Japan Institute of Metals, 118, 765-774.

[27] Cowley, J.M. (1950) An Approximate Theory of Order in Alloys. Physical Review, 77, 669-675. https://doi.org/10.1103/PhysRev.77.669

[28] Warren, B.E. (1969) X-Ray Diffraction. Addition-Wesley, Reading.

[29] Picha, R., Vrestal, J. and Kroupa, A. (2004) Prediction of Alloy Surface Tension Using a Thermodynamic Database. Calphad, 28, 141-146. https://doi.org/10.1016/j.calphad.2004.06.002

[30] Kaptay, G. (2008) A Unified Model for the Cohesion Enthalpy, Critical Temperature, Surface Tension and Volume Thermal Expansion Coefficient of Liquid Metals of bcc, fcc and hcp Crystals. Materials Science and Engineering. A, 495, 19-26. https://doi.org/10.1016/j.msea.2007.10.112

[31] Singh, R.N. and Sommer, F. (1997) Segregation and Immiscibility in Liquid Binary Alloys. Reports on Progress in Physics, 60, 57-150.

[32] Brandes, E.A. and Brook, G.B. (1992) Smithells Metals Reference Book. 7th Edition, Section 14.2, Butterwarth-Heinemann. 